\title{
La transmedialidad en las redes sociales como comunidades emergentes de conocimiento.De lo lúdico a lo trascendental. Aproximación etnográfica digital.
}

\author{
Jorge Sadi Durón ${ }^{1}$, Jorge Arturo Baca Velázquez
}

\begin{abstract}
Resumen
La comunicación, aunque parezca sólo entretenimiento o lúdica, guarda en sí misma, los mensajes y acciones de los agentes de todos los niveles, la raíz misma de las construcciones mentales y los recursos culturales de una sociedad red intercultural que comparte más contenidos, acciones e ideas de las que hemos creído hasta hoy. En esta investigación conjunta, docente-estudiante, cómo parte de una comunidad emergente de conocimiento científico desde la complejidad, los sistemas complejos, la epistemología genética y la cibercultur@, partimos de la premisa que, para entender los fenómenos sociales contemporáneos circunscritos en la sociedad red, o en red, debemos reestructurar las concepciones nomotéticas simplistas y entrar a la discusión de objetos-sujetos complejos, desde abordajes interdisciplinarios, entre dos o más comunidades de sujetos. Esto es una primera aproximación desde la comunicación, e integraremos más interesados en los mundos que nacen y construyen conocimiento desde las redes de usuarios, sobre los contenidos mediaticos y transmediaticos hacia los agentes audiencia que activamente reequilibra y construyen nuevo conocimiento a partir de esos productos comunicativos. Así, exponemos algunos ejemplos de la identidad en red y los complejos procesos de interacción entre individuos y tecnología, economía, Estado, movimientos sociales, la tecnicidad y colonialismo cultural. Mismos que no están exentos de las problematicas cotidianas de racismo, sexismo, homofobia, etc., y que pueden rastrearse a partir de los elementos autoreguladores que las propias comunidades han desarrollado dentro del contexto de un intercambio habitual de ideas, mensajes, discusiones, imágenes, "retos de combate", descripciones, etc. Esto nos lleva a pensar desde los sistemas complejos y la acción discursiva médiatica en los referentes o preconstruidos que podamos identificar a partir de sus construcciones de conocimiento, entre ellas, reglamentos, intercambio de duelos imaginarios entre personajes con superpoderes, entre otras.

Abstract

Communication, even though it seems like it is only for entertainment or ludic; contains in itself messages and actions of agents at all levels, the same root of all mental constructions, and the cultural resources of an intercultural network share by society. With more cohtent, actions, and ideas that we have been believers of up to date. In this combinated reaserch, teacher-student, which is part of an emergent community of scientific knowledge from complexity, complex systems, genetic epistemology and cyberculture; we started the affirmation that in order to understand the contemporary social phenomena regarding in a network society or just the network, we must reconsider and rebuild the simple nomothetics conceptions and get deeply into the debate of complex object-subject; from interdisciplinary approaches, between two or more communities. This is just a first aproximation viewed since the communication point of view, and we are going to invite more interested subjects in the worlds that are born and constructed from the users media about media and transmediatic contents towards the audience that actively balance and build new knowledge starting in those communicative proceses. Therefore, we present some examples of network identify and the complex proceses of interaction among individuals and technology, economy, State, social movements, technicity and cultural colonialism. The same that are not aparte from daily problems regarding racism, sexism, homophobia, etc., so that they can be trace able from the autoregulatory elements inside the same communities that have developed them in the context of the well known exchange of ideas, messages, discussion, images, "fighting networks", descriptions, etc. This takes us to think from complex systems and the media discourse action refering or prebuilt that we can identify starting from how their knowledge was built; among them: rules, fights between imaginary subjects with superpowers, among others.
\end{abstract}

Palabras Clave

Medios de comunicación, Sistemas sociales, sistemas de valores, Investigación en Comunicación

Keywords

Mass Media, Social systems, Value Systems, Comunication research

${ }^{1}$ CA. AIPP, FCPyS-UAdeC, Torreón

\section{Introducción}

En esta investigación conjunta, docente-estudiante, como parte de una comunidad emergente de conocimiento científico desde la complejidad, los sistemas complejos, la epistemología genética y la cibercultura, se parte de la premisa que para entender los fenómenos sociales contemporáneos circunscritos en la sociedad red o en red, se deben reestructurar 
las concepciones nomotéticas simplistas y entrar a la discusión de objetos-sujetos complejos, desde abordajes interdisciplinarios, entre dos o más comunidades de sujetos. Esto es una primera aproximación desde la comunicación, y habrán de integrarse más interesados en los mundos que nacen y construyen conocimiento desde las redes de usuarios, sobre los contenidos mediáticos y transmediáticos hacia los agentes audiencia que activamente reequilibra y construyen nuevo conocimiento a partir de esos productos comunicativos.

Se utilizará la Acción Discursiva Mediática, planteamiento teórico-metodológico de Jorge Sadi, para encuadrar un problema complejo representado en acciones cotidianas en el habitus de la interacción social dentro de las comunidades emergentes de conocimiento que se generan dentro de la plataforma Facebook. El trabajo etnográfico virtual y conocimientos de los grupos emergentes, son la especialidad de Jorge Baca. Así, se exponen algunos ejemplos de la identidad en red y los complejos procesos de interacción entre individuos y tecnología, economía, Estado, movimientos sociales, la tecnicidad y colonialismo cultural. Mismos que no están exentos de las problemáticas cotidianas de racismo, sexismo, homofobia, etc., y que pueden rastrearse a partir de los elementos autoreguladores que las propias comunidades han desarrollado dentro del contexto de un intercambio habitual de ideas, mensajes, discusiones, imágenes, "retos de combate", descripciones, etc. Lo anterior lleva a pensar desde los sistemas complejos y la acción discursiva mediática en los referentes o preconstruidos que se puedan identificar a partir de sus construcciones de conocimiento, entre ellas, reglamentos, intercambio de duelos imaginarios entre personajes con superpoderes, entre otras. Lo que llama la atención es que a partir de esa convivencia mutua y consensual también se dan discordancias debido a los problemas sociales aquí comentados y que lleva a preguntar: ¿qué motivos influyeron en que las comunidades emergentes de conocimiento de los cómics construyen mecanismos de protección representados en acciones y normativas con respecto a su operatividad dentro del grupo de Facebook?

Es decir, cómo se puede describir el habitus de la interacción social en los grupos de Facebook, autoorganizados por agentes diversos (en todo aspecto, geográfico, social, edad, género, etc.), con el fin de compartir conocimientos, información y comunicación, de sus personajes, historias y estereotipos transmediáticos del cómic, el cine y la web. Esta función social y psicológica, se ve reflejada en el sistema simbólico que emplea, puesto que la misma internet utiliza además de lenguaje hipertextual y gráficos, el lenguaje simbólico humano en todo su esplendor, metalingüísticamente hablando. Son escenarios nuevos y fascinantes por conocer.

La acción discursiva mediática no es exclusiva de los agentes del medio de comunicación tradicional, así como de los periodistas y comunicólogos; existen ahora también audiencias que producen sus propios contenidos o que debaten entre ellos en sus mundos de tiempo-espacio flexible. Las características de la pluridimensionalidad del discurso de agentes que pueden ser ficción, fantasía, arte o, simplemente, preconstruidos, simbologías, identidades adquiridas que se reflejan en sus propios argumentos.

Esto lleva a una premisa del modelo teórico-metodológico a emplear: las investigaciones complejas deben ser interdisciplinarias y de preferencia con grupos de trabajo. En este primer acercamiento al fenómeno de las transmedialidad del comic al videojuego y de ahí a la audiencia que construye y resignifica, a partir de comunidades emergentes de conocimiento, desde otra plataforma, en este caso la red social de Facebook, por Facebook groups, surgen con otras acciones y reglas que son reequilibraciones culturales de capital simbólico, desde el agente audiencia y transmisiones de tercer nivel desde un grupo de sujetos afines a los productos mediáticos del comic, los videojuegos, películas, etc. Viven y hacen su propio mundo de acciones discursivas mediáticas y transmediáticas.

La transmedialidad es ese objeto de comunicación que ha trascendido el lenguaje y la racionalidad comunicativa de su propio medio y, ahora, no sólo se escribe desde los medios a las audiencias, sino desde las audiencias a las propias audiencias, en comunidades propias, donde el significado o el canon, puede o no ser flexible, y puede o no reestructurarse en algo nuevo, lejos o muy cerca del canon empresarial o ficcional.

La transmedialidad, ahora mediáticamente hablando, no es exclusiva del que produce los medios originales de la historia, sino que comparte las narrativas y sociocogniciones propias y de sus audiencias en un ciclo de reconstrucciones de la realidad que es intersubjetivamente mediadora, a partir de la mediatización del sujeto audiencia, en su propia trinchera o 
su propio mundo de construcciones simbólicas, a través no sólo de letras, sino de acciones y de interacciones sociales y psicológicas, como lenguaje hipertextual, a través de las redes sociales digitales.

A partir de la Acción Discursiva Mediática y su metodología, se identifican como reto cuatro fases de aproximación y resultados que son ocho momentos: Serán 4 etapas: 1) Exploración y acercamiento; exposición de resultados iniciales y aproximación secundaria (descriptiva-exploratoria, contextual). 2) Entrevistas semiestructuradas y observación directa, transcripción en texto y tablas (acercamiento etnográfico digital, por chats rooms, grabaciones de audio o video, etc.). 3) Captura y estructuración de los datos, concatenación de cifras-acciones-discursos (recopilación de datos, clasificación de las categorías que surgirán a partir del propio sujeto-objeto de estudio). 4) Análisis desde la acción discursiva mediática y exposición de resultados (acciones convertidas en discursos textuales, entendidos como: imágenes, convenciones propias del idioma y lenguaje de redes, publicaciones, fotos, comparativas de combates, entre muchas otras).

A continuación se presentará la Fase 1 de esta investigación desde el paradigma de los sistemas complejos y la epistemología genética.

\section{Aproximación desde las ciencias sociales a los estudios complejos}

Las ciencias sociales, cada una por separado, no pueden dar cuenta -sin limitarse- de los intrincados fenómenos sociales, que, a metáfora y realidad de la informática, se despliegan en redes virtuales y físicas, que llevan a pensar lo social en interacciones cada vez más técnicas, cada vez más complejas, y cada día más mediadas por agentes y campos del saber digital.

Las ciencias sociales se identifican como un conjunto de disciplinas del pensamiento encaminadas a estudiar los fenómenos humanos dentro de un ambiente dado, en el cual está inmerso de manera voluntaria o involuntaria los individuos y los investigadores, pero, que involucra indefectiblemente, la relación e interacción entre individuos. Se intentará dar un panorama de lo que las ciencias sociales son, de mano de Immanuel Wallerstein.
Las ciencias llamadas sociales, están por una parte integradas por la historia que se preocupa de investigar a las civilizaciones que tienen documentado su progreso a través de la palabra escrita. Por otro lado, están las tres ciencias duras (nomotéticas) la sociología, la economía y la ciencia política. Esto dentro de la configuración clásica de la universidad del siglo XIX. La ciencia social dividida en tres estratos (ciencias naturales, ciencias sociales y humanidades), da nacimiento a la "otra" ciencia, la que estudia "todo" de los otros, de los que "no se conoce nada y son ahistóricos": la antropología, que desde un posicionamiento colonial debía producir conocimiento, investigación y universitarios que se encargaran de abordar a los que se encontraban fuera y dentro de los límites coloniales de las grandes "civilizaciones occidentales" (Francia, Alemania, Gran Bretaña, las Italias y Estados Unidos) y los estudios orientales que abarcaban a otras civilizaciones no occidentales y que si tenían historia escrita (Wallerstein, Immanuel., 1995).

A estos Wallerstein les llama los estudios multidisciplinarios, y aparecen después de la segunda guerra mundial, sobre todo de los Estados Unidos, por una motivación de tipo geopolítica:

"Surgen entonces los estudios de áreas como modo de organización mediante el cual se pueden producir con rapidez gran número de investigadores que llegan a acumular algún saber sobre África, Asia, América Latina, Rusia China y cualquier otra región... Si se estaba interesado en la India, tenía entonces que aprender algo de historia de la India, de la sociología de la India, de su economía, de su ciencia política. Después podía estudiar el idioma urdu o hindi, o lo que fuese. Esto se llamó - para usar la expresión ya consagradaestudios multidisciplinarios. (Wallerstein, Immanuel., 1995)

Pronto estos estudios buscaránn también las tribus internas de las grandes naciones occidentales, y precisamente, el siguiente cambio que se genera es en las áreas de estudio de las ciencias sociales, ciencias naturales y humanidades.

Es en la década de los años setenta que así mismo sufre un cambio de posicionamiento la ciencia en general, puesto que el entendimiento de la ciencia y, epistemológicamente hablando, de su método a partir de una lógica Newtoniana Lineal-mecanicista, se revalora y permite una reinterpretación del campo, ya que las "verdades universales" o la "realidad" no es más que una suerte de "afirmaciones probabilísticas", ya 
que hasta las leyes de "la naturaleza misma son reversibles". El paso del tiempo "sí, altera la ley natural", desde los átomos hasta los fenómenos sociales, y por ello, el físico y el sociólogo pueden verse a la par, (cuando antes había una clara visión de menosprecio hacia lo social), y hoy día, los mismos físicos saben que lo "social es más complejo", "bifurcado" y no lineal. Los estudios de humanidades dieron pie a los estudios culturales, los cuales, son representativos de la complejidad, y los investigadores de esta área, incluso llegan a ponerse entre las humanidades y las ciencias sociales como un "proceso social más” (Wallerstein, Immanuel., 1995).

Siguiendo a Wallerstein se puede intuir que la ciencia debe realizar un reacomodo, o al menos una revisión de la forma en que se realiza la investigación en las diversas áreas de las ciencias sociales, la "particularización" de lo social en divisiones que obedecían a la lógica liberal tripartita "sociedad/sociología, estado/ciencia política, mercado/economía" (Wallerstein, Immanuel., 1995) debe cambiar, así como el pensamiento lineal de la historia, que observa una forma de tiempo o de "evolución social" que surgirá a partir de la tecnología y el desarrollo de los pueblos hacia la democracia y por supuesto al capitalismo como eje, que en América Latina se recibe de la herencia del "eurocentrismo" (Quijano, 2000).

\section{De la multidisciplina a la interdisciplina}

Una forma de abandono de los paradigmas simplistas es la interdisciplinariedad, que en las investigaciones científicas contemporáneas intenta "delimitar" objetos de estudio complejos y lejos de las visiones colonialistas del conocimiento. Formas de comunicación alternativa (Sadi Durón J. , 2006) que permiten dialogar a las audiencias más allá de los medios tradicionales, en la formación de sus propias redes de construcción de conocimiento.

Dentro del pensamiento alterno (en este caso los estudios culturales), se puede encontrar respuestas y claves para pensar la diversidad cultural y para conceptualizar la ciencia social desde lo interdisciplinario. No se trata de derribar la ciencia existente, sino de hablar en términos de equidad epistemológica, con cuerpos teórico metodológicos que aborden los fenómenos sociales y comunicativos, con posicionamientos no lineales y sobre todo pensados desde el paradigma de los colonizados, y no de los colonizadores.

La interdisciplinariedad así entendida, abre el camino a entender los fenómenos de la comunicación, desde una perspectiva crítica, pero no determinista científico-empirista, no conductista, y a los sujetos como seres partícipes de un sistema mundo, pero con sus propias características socio-histórico-culturales, que lo posicionan de modos distintos a los teorizados para las realidades occidentales. Es decir, el fenómeno es complejo y el agente o sujeto social lo es también, a igual que las construcciones sociocognitivas que realiza desde sus esquemas de acción, pensado desde lo bio-psico-social (García, 2006).

La sociedad, los agentes, la comunidad, los campos de conocimiento, las trayectorias sociales, los capitales culturales, todo está interconectado, y no tienen por qué separarse, salvo por cuestiones científicas de delimitación en la búsqueda de resultados, pero sin dejar de pensar que esos resultados son parte de un todo. Se construyó conocimiento a partir de muchas partes del todo y de nosotros mismos. El colonialismo simbólico está ahí, pero también, nuestras perspectivas no-coloniales, más que apartar, hay que integrar, asimilar, acomodar y reequilibrar la episteme de la construcción de conocimiento de las ciencias sociales.

Para ello, la teoría de los sistemas complejos de Rolando García (García, 2006), y la Epistemología Genética de Jean Piaget (Piaget, Inhelder, García, Vonéche, 1981), ayudan a partir del constructivismo, que desde las aproximaciones y alejamientos hechas del sujeto-objeto-sujeto, sin olvidar que los investigadores deben de entenderse a sí mismos, como parte de la red semántica o red de significados, significantes y significaciones, que se entrelazan como preconstruidos fruto de los capitales culturales entendidos desde Bourdieu (Bourdieu, 2008), y de la racionalidad comunicativa de sus actos de comunicación desde Habermas, que como acción comunicativa (Habermas, 1981) se despliegan en diversas plataformas de niveles humanos de comunicación (Jensen, 2014) y metahumanos, es decir, la mediación (Vigotsky L. S., 1978) y mediatización (Krotz, 2009), a partir del contacto cara a cara, con los medios de comunicación y sus lenguajes; la lengua misma (Vigotsky L. , 1977) del que construye el conocimiento a transmitir; del contacto con otros agentes dentro de su medio y sus sociocogniciones. 
Así como de las estrategias para comunicar, los preconstruidos semióticos, cognitivos, sociales, culturales, etc. (Haidar, 2006), que al momento de trascender del agente al medio y del medio a las metatecnologías, como internet y las redes sociales digitales, ya no se trata sólo de emisores-mensajes y recepción, sino de constructores que transmiten información, en forma de comunicación, por un sistema complejo, y que llegan a uno o millones de sujetos agentes del espacio social y otros campos; mismos que reaccionarán ante dichos mensajes y emiten su propia construcción y deconstrucción del conocimiento al que son expuestos, y reconstruyen, o asimilan y adaptan, o rechazan, para compartirlo a su vez con otros agentes audiencia que como ellos, son activos y no sólo pasivos de la comunicación red (Sadi Durón Zapata Salazar, 2020).

Todo esto se plantea desde la perspectiva integradora de la acción discursiva radiofónica (Sadi Durón Zapata Salazar, 2020) adaptada a los otros medios, para poder hablar ahora de "acción discursiva mediática". Construcción teórico-metodológica que está en fase final de exposición de la tesis doctoral del investigador Jorge Sadi, por publicarse.

\section{La sociedad en red}

La sociedad red (Castells, 2001) o la sociedad en red (Sassen, 2010), es una forma de concebir a este nuevo fenómeno económico, político y socio-históricamente mediado por las computadoras e internet. Tecnología que genera procesos de comunicación y producción (laboral) que afectan o modifican la cultura desde sus instituciones base (Latour, 1998). ¿Cómo afrontan las ciencias sociales este desafío de cara a un objeto de estudio complejo del cual escapan las variables de control a los científicos, y se conforma más allá de los determinismos, pero muy cercanos a la mediación técnica que es mutuamente interdependiente y mutable?

La realidad entendida desde la ciencia moderna, no puede sostener ya el estudio de fenómenos complejos sin salir del ostracismo científico, la posible respuesta a este repensar la manera de hacer la ciencia y en especial las ciencias sociales, va de la mano de la interacción coordinada de los diferentes campos científicos de investigación (Wallerstein, 1998). Un replanteamiento epistemológico que tiende a la interdisciplinariedad y que en el caso de la comunicación, como disciplina en proceso de creación. La acción discursiva mediática, va por ese camino de la complejidad e interdisciplina entre agentes de la ciencia. La interacción disciplinar o convergencia de ciencias, es sobre un objeto a veces tan inasible como lo es la comunicación, que cruza todas las ciencias y parece no poderse forjar una en específico, y tal vez esto no sea lo deseable.

\section{Los investigadores y el contexto de investigación en red}

El papel del investigador, acorde a lo leído, debe ser el de uno o varios intelectuales de diversas disciplinas que deconstruya el conocimiento existente con respecto a la realidad latinoamericana y mundial. Si bien, emplear los conceptos teóricos existentes, hacerlo con las salvedades, y por supuesto repensarlo y construir los propios, darle la importancia y privilegiar las filosofías y conceptualizaciones emergentes de los países "colonizados" y en vías de “descolonización”, y abrir el panorama a las explicaciones alternas que surgen de la interculturalidad o mejor dicho de la diversidad cultural, en la que conviven y escapar de la uniformidad del pensamiento occidental blanco, hacia una multiplicidad de pensamientos asiáticos, africanos, árabes, mexicanos, brasileños, etc.

Se debe de explicar la historia global o universal del mundo humano, desde la localidad, diferenciándola de los patrones europeos y norteamericanos, brindarle el lugar que debe tenerse, sin cosificarlos, estableciendo una epistemología propia y una ética acorde a la naturaleza cultural de nuestro entorno. La realidad de una región como la llamada Lagunera que es parte de dos entidades distintas y que convergen a su vez, Coahuila y Durango, es muestra de cómo esas manifestaciones globales, pueden enfocarse en problemáticas locales, como el uso de las redes sociales y desde ellas mismas. Como dice Nir: "La estructura regional es dada por los elementos mentales de la Región que, por medio de los reguladores (accesibilidad, topo-grafía, clima, capacidad económica, ventajas culturales, entre otros), se convierten en elementos del paisaje visible." (Mateo Rodriguez Bollo Manet, 2016, pág. 43). 
La defensa de la cultura, la apropiación de los medios para "rescatarla" y "apropiarse" de las herramientas conceptuales desde una perspectiva latinoamericana -no europeizante o anglosajona- para explicarlas es la labor actual. Es un marxismo renovado, marxismo gramsciano que otorga dentro de una realidad capitalista, la preeminencia a los movimientos sociales de las "minorías", y redescubrir el entramado social de este continente, apropiado a la diversidad originaria y de las visiones cosmopolitas propias, con un marco conceptual específico para la realidad y preocupaciones, desde una "hermenéutica profunda" (Thompson, 2002). La complejidad de Morin, la hermenéutica profunda, las teorías de sistemas y sistema mundo, son posicionamientos que si bien no pertenecen per se al pensamiento latino, se han incorporado de manera adecuada, por su posicionamiento socio-antropológico inclusivo, que involucra lo objetivo-subjetivo y que provee de los parámetros necesarios para un acercamiento de la ciencia social a la realidad actual (entendida como de esta época) y sus matices y contradicciones inherentes, que son, aunque suene a eufemismo, "la realidad moderna de cambios acelerados" (Antonio, 2009).

Hay una apertura al acceso de interacción y colaboración por internet, pero los medios técnicos y las condiciones materiales de bienestar para emplearlos no son o están al alcance de "todo el pueblo": educación, servicios básicos, empleo y por supuesto tecnología barata (Sassen, 2010). La revolución informática se da en las zonas urbanas o superpobladas, no así tan fácilmente en el campo, las zonas marginales, etc. Internet llega hasta donde las antenas lo permiten (Strathern, 1996) y generalmente las antenas están en manos de unos cuantos concesionarios que se enriquecen gracias al monopolio y desregulación estatal, motivado por las políticas neoliberales, en detrimento de la sociedad y en beneficio del poder y el capital social de actores con intereses particulares. A palabras de Bourdieu:

“...el poder de los agentes e instituciones que hoy dominan el mundo económico y social se asientan sobre una concentración extraordinaria de todo género de capital, económico, político, militar, cultural, científico, tecnológico, fundamento de una dominación simbólica sin precedentes, y que se ejerce en particular a través del dominio de los medios de comunicación que a su vez están manipulados, sin muchas veces saberlo, por las agencias de comunicación.”. (Bourdieu, 2006)

Este avance tecnológico, la concentración del poder y sus consecuencias, se pueden reconocer en múltiples etapas y sociedades (a lo largo de la historia humana), que con el advenimiento de un instrumento, herramienta, método o modo de producción, generaba esta implicación de cambio y adaptación (Wallerstein, 1998). Esto no es algo nuevo, pero lo que sí ha pasado es que se ha dado de forma más acelerada.

La herramienta no hace al obrero, pero determina el "qué trabajará", "cómo trabajará", "cuánto trabajará” y "dónde trabajará". La informatización de la sociedad, trae a materia digital qué se trabajará, en ambientes virtuales, sin horarios fijos, y en locaciones geográficamente estables y dispersas, pero involucradas en tiempos globales con presencia mundial. En cuanto a los investigadores Latour dice: "El idéntico error de materialistas y sociólogos es partir de las esencias, las de los sujetos o las de los objetos. Ese punto de partida hace imposible que se pueda medir el papel mediador de las técnicas. Ni el sujeto ni el objeto (ni sus metas) son fijos" (Latour, 1998, pág. 254) Sujetos y objetos conviven e interactúan, así se conforman patrones identitarios.

Cassirer (2007) habla de que el hombre a partir de este sistema de símbolos vive en un mundo artificial, puesto que está fabricado de ilusiones, emociones, esperanzas, además de la comprensión de los fenómenos físicos y de las decisiones racionales. La poesía y la ciencia, el lenguaje descriptivo $\mathrm{y}$ el literario, todo es un entorno que el hombre utiliza y maneja para sí mismo y para con los demás (pág. 21). El lenguaje humano ha permitido al hombre interactuar de manera más efectiva y transmitir, esas ideas, pensamientos, emociones, sueños y toda suerte de imaginarios, que han dado a la existencia humana un carácter especial y espacialmente adecuado a su condición racional y a su condición emotiva. "La razón es un término verdaderamente inadecuado para abarcar las formas de la vida cultural humana en toda su riqueza y diversidad, pero todas estas formas son formas simbólicas" (Cassirer, 2007, pág. 47).

Es decir, para entender al ser humano, la ciencia dura o las operaciones prácticas no son suficientes, y el lenguaje emotivo, las características inherentes a la condición humana, se cristalizan en las producciones simbólicas adyacentes a su 
carácter de comunicación e interacción humano. El símbolo es sentido y la señal es un valor funcional.

El ser humano produce sin cesar diferentes sistemas de comunicación, es decir, plataformas, puesto que la comunicación en sí como fenómeno no se altera, sólo cambia la plataforma en la que se transmite. Se pasa de la producción del lenguaje a diversos modos de transmitirlo, la historia de los medios es conocida y es menester de esta investigación el encargarse únicamente de lenguaje que emplea el ser humano y de los símbolos que participan de esta interacción humana a través de internet.

El hombre a partir de este sistema de símbolos vive en un mundo artificial, puesto que está fabricado de ilusiones, emociones, esperanzas, además de la comprensión de los fenómenos físicos y de las decisiones racionales. La poesía y la ciencia, el lenguaje descriptivo y el literario, todo es un entorno que el hombre utiliza y maneja para sí mismo y para con los demás. El lenguaje humano ha permitido al hombre interactuar de manera más efectiva y de transmitir, esas ideas, pensamientos, emociones, sueños y toda suerte de imaginarios, que han dado a la existencia humana un carácter especial y espacialmente adecuado a su condición racional y a su condición emotiva (Cassirer, 2007, pág. 47). Como dice Cassirer, "La razón es un término verdaderamente inadecuado para abarcar las formas de la vida cultural humana en toda su riqueza y diversidad, pero todas estas formas son formas simbólicas" (Cassirer, 2007, pág. 47). Es decir, para entender al ser humano, la ciencia dura o las operaciones prácticas no son suficientes y el lenguaje emotivo, las características inherentes a la condición humana, se cristalizan en las producciones simbólicas adyacentes a su carácter de comunicación e interacción humano. El símbolo es sentido y la señal es un valor funcional.

El ser humano produce sin cesar diferentes sistemas de comunicación, es decir, plataformas, puesto que la comunicación en sí como fenómeno no se altera, sólo cambia la plataforma en la que se transmite. Pasamos de la producción del lenguaje a diversos modos de transmitirlo, la historia de los medios es harto conocida y es menester de esta investigación el encargarnos únicamente de lenguaje que emplea el ser humano y de los símbolos que participan de esta interacción humana a través de internet.

\section{Las redes sociales digitales: Facebook}

Para muchos las redes sociales, en internet, son sinónimo de comunicación, plática, chat, fotos, etc. Sin embargo, redes sociales es un término que acarrea comunicación e interacción y relaciones cercanas entre individuos, con ciertas características especiales, marcadas por el empleo de una tecnología y de la virtualidad del contacto humano.

La red social en internet es un lugar donde se encuentran los conocidos, amigos, familiares, alumnos y maestros en relaciones como compañeros de tendencias políticas, religiosas, musicales, ideológicas, lúdicas, sociales, etc. Pero también donde se discrimina, selecciona, sintetiza la realidad y las preferencias, a partir de un perfil específico, que va marcado por múltiples factores de diversa índole, como la edad, el sexo, la demografía (paradójicamente), etc.

\section{El concepto de red social}

Para partir de un sitio específico del mapa, valga la metáfora geográfica en la complejidad conceptual del término:

El término de red social implica, entonces, un sistema abierto a través de un intercambio dinámico entre sus integrantes y con integrantes de otros grupos, que posibilita la potenciación de los recursos que se poseen y que se enriquecen con las múltiples relaciones entre los diferentes miembros que las componen. Las redes sociales son, en esencia, procesos dinámicos a través del tiempo y de las circunstancias sociales concretas. (Madriaga Orozco, Abello Llanos, Sierra García, 2014, pág. 12)

Las redes sociales así definidas, permiten vislumbrar un panorama que va más allá de la simple formulación de una teoría sería, pensada sólo en los contenidos políticos o de imperialismo cultural, a final de cuenta, la apropiación de aspectos de una cultura a otra, es algo inherente de la mayoría de las culturas que intercambian conocimientos, artes, ciencia, técnicas, religiones, dioses, creencias y héroes, por mencionar algunos aspectos antropológicos desde lo social (Manm, 2002). Dentro de estas apropiaciones están las redes sociales, los juegos, los cómics, los videojuegos, las películas y muchos otros elementos lúdicos, porque "una cultura auténtica no puede subsistir sin cierto contenido lúdico... (Huizinga, 2007, pág. 268), que ya en sí es importante, y remiten a múltiples factores sociales, psicológicos, semióticos y culturales, que 
ponen en alerta ante estas nuevas plataformas de contacto cultural. Como dice Martin Barbero sobre el saber de los jóvenes, "es más visible en los jóvenes y que legitima el conocimiento más allá de la escuela, y el saber ahora es difuso y no centralizado..." (Barbero, 2002) porque el saber, el jugar, el aprender, el intercambio simbólico y de narrativas conceptuales se da en la instantaneidad de la red global, desde la comodidad del hogar o la ubicuidad que otorga el gadget o "artefacto cultural" (Baudrillard, 2007) de la laptop, el teléfono inteligente, entre otros dispositivos que permiten la comunicación a mediada a través de ordenador (Hine, 2004) y a través de individuos, en redes de conocimiento emergentes, en torno a temas variados y variables, pero que congregan a los sujetos en comunidades de conocimiento, información y comunicación, con interacción simbólica, más allá de compartir contenidos, sino compartir sistemas de contenidos y de construcción del conocimiento, es decir, cibercultura (Almaguer Kalixto, 2013).

Una comunidad emergente de conocimiento desde la cibercultura es más que compartir la cultura, es, interactuar en la reconstrucción y equilibración de nuevo conocimiento en torno a esos esquemas de acción, racionalidad comunicativa, narrativas de acciones y de sociocogniciones, que a través de las redes simbólicas mediatizadas y mediatizantes, generan sus propios lenguajes, con base al lenguaje propio, el de otros agentes y los preconstruidos de sus estructuras mentales, convertidas en racionalidad comunicativa, que han sido influenciadas por su trayectoria social, capitales culturales, simbólico, sociales, entre otros y que se despliegan en el medio en el cual se desenvuelven (Sadi Durón Zapata Salazar, 2020). En este caso, las redes sociales de internet, como Facebook, que tiene a su vez grupos de agentes que se juntan por afinidad y deseo de hablar de temas que van desde lo socialmente trascendente, lo filosófico, hasta lo lúdico, lo cómico o lo irrelevante o intrascendente, que para ese grupo, en sí, cobra cierta importancia.

Hay una mirada positiva y otra mirada crítica, de las redes sociales en cuanto al uso de las redes sociales. Por un lado, se habla de la extensión de las características democráticas de la red, la posibilidad de interacción y de publicación de material por parte de cualquier personaje que cuente con un ordenador y acceso a internet. Por otro lado, la visión crítica, que nos plantea que aunque cualquiera puede acceder, este aún está limitado por cuestiones económicas, de conocimientos, y de filtros de protección de derechos de autor y de usuarios de las propias redes sociales (Twitter, Facebook, Youtube, etc.), y múltiples opiniones sobre los contenidos, que se podrían clasificar en una docena de casos, pero que van encaminados a la diversidad cultural y el uso social de las plataformas, su libertad e interacción.

Facebook tiene una estructura económica imperialista y en un marco de uso social, pero bajo la conceptualización mercantilista de un discurso dominante que se evidencia en sus herramientas y características particulares de interfase que es un medio de comunicación de tercer nivel, es decir "metatecnología" (Jensen, 2014) mediador de mediadores, transmediador.

Los cómics son un medio de comunicación tecnológico de segundo nivel (Jensen, 2014, págs. 17-24), que ha pasado de la mediación de medio tradicional de prensa, a otros medios, respetando en ciertas ocasiones su historia original y en otras adaptándose, por agentes de primer nivel (cara a cara y de segundo nivel, mediáticos-editoriales) precisamente por la mediación de los lenguajes diferentes que tiene que enfrentarse la acción discursiva mediática (Sadi Durón Zapata Salazar, 2020) que el agente operador de medios de segundo nivel tiene que adaptar para resimbolizar la narrativa del comic de papel a la narrativa de la televisión, a la de la radio, y por supuesto a la del cine e internet y la narrativa visual digital.

Para poder acercarse a un mundo simbólico digital, donde las interacciones son imposibles de predecir $\mathrm{y}$ complicadas de seguir, se debe de abordar una perspectiva de etnografía virtual, que sirva para aproximar a esos "grupos comunitarios" desde su propia plataforma con reglas de acción e interacción, lenguaje, caló, narrativas y formatos de plática, resignificaciones y variables preconstruidas. Por tanto se proponer una aproximación a la perspectiva etnográfica virtual desde las redes sociales.

\section{El simbolismo y la inserción a la vida simbólica a través de la etnografía en Facebook. Acercamiento metodológico complejo}

Desde la acción discursiva mediática, se puede entender las formas simbólicas de cada sociedad, o de cada grupo social, 
si no como "únicas", sí, en esencia particulares, aunque entre todos los grupos humanos hay similitud de procesos y de características que se pueden identificar a través de su arte, sus jerarquías sociales, su vida familiar, sexualidad, etc. (Manm, 2002). El patrón de comportamiento de cada sociedad, y por lo mismo su capital económico y su capital cultural (Bourdieu, 2008).

La antropología plantea que las sociedades tienen en su interior, subgrupos integrados por edad, género, clase social, creencia religiosa, ideología, etc., que los une en un patrón de comportamiento similar, con ciertas reglas, vestimentas, costumbres y estructuras de pensamiento, que pueden apreciarse a través de distintas variables: vestimenta, rituales, música, ceremonias, festividades, literatura, arte, lenguaje, etc.

Estas subculturas se pueden localizar, caracterizar, identificar y describir, gracias al estudio antropológico, por el método de la etnografía, el cual, a partir de la inserción de un sujeto observador-participante, en un núcleo social durante al menos 2 años, permitirá obtener resultados sobre el comportamiento emic de los actores de la subcultura, comunidad o grupo de personas que a partir de una perspectiva etic, realizará su análisis y descripción, la cual, será enriquecida con las vivencias emic del observador dentro de su papel como participante (Manm, 2002, pág. 87).

Las representaciones simbólicas, entonces se pueden identificar en este caso en los productos o manifestaciones que se presenten en las plataformas virtuales o redes sociales, donde los individuos participan de esta subcultura, que tiene ciertas reglas, lenguaje, normas, políticas, y otra surte de patrones culturales. La naturaleza de este capital cultural, es el que importa en esta investigación, puesto que no se sabe a ciencia cierta, cuál es el origen de las manifestaciones culturales visibles en las redes sociales, en particular, para este estudio se enfocará en Facebook, por ser la que reúne la mayor parte de los atributos de la moderna web 2.0, que comparte las funciones que tenían las otras formas simbólicas de internet (Messenger fotos, links, videos, etc.), además de incorporar sus propios productos culturales para definir patrones de gusto, de sentimientos, etc. (me gusta, ya no me gusta, dar un toque, etc.)

La vida social real es filtrada por las redes sociales, y la comunicación pasa de ser un simple sistema de mensajerías por mail, para ser un estilo de vida, con valores, manifestaciones ideológicas (grupos, ideología, etc.), donde el usuario define posicionamientos, nacionalidad, ideología, gustos estéticos, emocionales, etc., algunos definidos, por una lista que mayoritariamente provee el servidor Facebook (en algunos casos) y no sólo el usuario, reglamentos de uso y servicio, basados en los parámetros éticos de Facebook y de los usuarios de los grupos de Facebook como comunidades emergentes de conocimiento (Almaguer Kalixto, 2013).

La intimidad del sujeto, su trabajo y formación, sus funciones corporales, sus deseos más íntimos, su sexualidad, sus prioridades, sueños, gustos, todo es externalizado en el mundo de la virtualidad, es decir, parte de la trayectoria social del sujeto y de sus capitales están presentes en su "perfil e historias" de Facebook, Instagram, en el Twitter, en el Whats APP y Messenger de Facebook, por mencionar los más conocidos, "en la maquina <todo estará escrito $>$, tendrá lugar un desdoblamiento simbólico completo de la realidad" (Žižek, 1999, pág. 172). La realidad social sigue en la calle, pero el remanente simbólico-virtual (aunque todo es virtual) que se despliega en la red, es cada vez mayor y vulnerable a los ataques tanto como lo es en la cotidianidad de carne y hueso.

A partir de la herramienta nacida de la Etnografía Virtual (Hine, 2004) a la que se llamará: la observación digital virtual, se permite corroborar hasta cierto punto las acciones realizadas por algunos de ellos y contrastar los resultados de lo cuantitativo con la observación digital virtual.

Pero la aplicación de la misma, ha sido pensada desde la antropología social (Manm, 2002), a partir de la etnografía y la etnografía de la comunicación desde el análisis mediático del discurso, "el AMD se centra más en la acción social que en el discurso o en el lenguaje" (Scollon, 2003, pág. 206) que también es compatible con Bourdieu y el entramado teórico aquí presentado. Dadas las circunstancias de aislamiento y distanciamiento social, el acercamiento ha sido a partir de la etnografía virtual, que es "una particular aproximación etnográfica que no es igual a la de la vida "real" pero se le parece mucho..." (Hine, 2004, pág. 20). Esta aproximación es posible, ya que el investigador utiliza las mismas herramientas digitales de trabajo, plática e interacción que los agentes de los medios, que son los informantes, de lo que es una "etnografía móvil y multisituada" que 
permite atravesar, tiempo y espacio casi ubicuamente, que las personas que se encuentran geográficamente dispersas en una comunidad amplia, pero presentes casi instantáneamente, se interrelacionen e interaccionen.

Como dice Hine (2004) en referencia a la etnografía virtual como enfoques, el primero a partir de la "Comunicación Mediada por Computadoras (Computer-Mediated Communication- CMO)" donde el "ciberespacio es un lugar plausible para realizar el trabajo de campo" y el enfoque de internet como "artefacto cultural (Woolgar, 1996), un producto de la cultura, en fin: una tecnología que ha sido generada por personas concretas, con objetivos y prioridades contextualmente situados $\mathrm{y}$ definidos y, también conformada por los medios en que ha sido comercializada, enseñada y utilizada" (Hine, 2004, págs. 18-20).

La red, es vasta y no todas sus regiones exploradas. Tomando en cuenta el centralismo de la investigación, es el territorio más familiar de encuentro para investigaciones desde lo "virtual", pero es realizado desde localidades geográficas metropolitanas, lejos de otros sujetos geográficamente distantes del interés científico, que no sea de la propia región o cercanía. Es por ello que se tiene la oportunidad de darse cuenta que ya se puede y se debe, intervenir de manera etnográfica digital, con los medios de comunicación y los agentes del mismo; ya sea porque eres parte de los propios agentes del campo, o a las redes cercanas a ellos, o las redes públicas que los propios medios y sus agentes, "suben” para dar seguimiento y retroalimentación a sus "seguidores".

Así como agentes del medio virtual y sus redes en Facebook, los investigadores se acercaron a otras trayectorias sociales, que forman parte de los contactos conocidos en la propia red de Facebook y Whatsapp de los investigadores. Pudiendo cumplir la perspectiva Emic y Etic de la investigación antropológica, como observador participante y al mismo tiempo como investigador (Manm, 2002). El muestreo realizado fue por criterio lógico, implica trabajar todos los casos que reúnan algún criterio predeterminado de importancia (Sandoval Casillimas, 1996, pág. 124). También llamado muestreo intencionado, al ser el investigador quien decide por su juicio, los elementos representativos para ser estudiados (Behar Rivero, 2008, pág. 53). Los personajes o agentes observados podrían reconocerse como mujeres, hombres o no identificados, debido al anonimato que da la propia creación de un perfil y que, desde ahí, ya es una sociocognición y construcción de conocimiento a la que se logró acercarse.

\section{Acercamiento al campo de estudio y su lenguaje particular: transmediación semiótica del comic-al videojuego y del consumo al grupo de Facebook; "la narrativa dispersa de Injustice", acercamiento etnográfico virtual}

Hablar de transmediación implica abordar antes el concepto de mediación; aunque ambos compartan el sufijo "ción" (acción y efecto), distan de significar lo mismo. La mediación, en palabras de Elleström, es "a pre-semiotic, physical realization of entities (with material, sensorial, and spatiotemporal qualities, as well as semiotic potential) perceived by human sense receptors within a communication context" (Elleström, 2017, pág. 688) es decir, el espacio donde se significa algo que se ha simbolizado, traducido como: "una realización presemiótica y física de entidades (con cualidades materiales, sensoriales y espaciotemporales, así como potencial semiótico) percibidas por receptores de sentido humano dentro de un contexto de comunicación"

Acorde a Garza, se simboliza a partir de factores sociales y psicológicos, aunado a los marcos de referencia del emisor para dar a significar algo (Garza Cuarón, 1999, pág. 11). Lo que Pierce llamaría representamen (Peicer, 1986). Como muchos prefijos que surgieron como adverbios, el de -trans “en latín poseía una función sémica específica de carácter traslativo ('de un lado a otro')” (García Sánchez, 2017, pág. 124), lo que actualmente se connota como "más allá".

Tratando de formular una definición, la transmediación es el proceso por el que una simbolización es emitida en más de un medio de comunicación. Y como Guarinos, citado por Peña: afirma, "no puede ser entendido como apropiación indebida, ni como imitación ni como falta de recursos propios de un determinado medio", por lo que dista mucho de ser una adaptación, debido a que esta toma una idea original para trasladarla a otro medio; (...) diría que una adaptación

\footnotetext{
${ }^{1}$ NOTA: A menos que se indique lo contrario, todas las traducciones son de nuestra autoría.
} 
audiovisual es una recreación original, por cuanto el resultado final de la adaptación es (o por lo menos debe ser) original y creado (de nuevo) sobre una sustancia expresiva diferente de la obra original primera, lo que implica un conocimiento con detalle de dos códigos expresivos y de dos técnicas y métodos creativos diferentes. (Peña Timón, 2003, pág. 1)

En cambio, hablar de transmedialidad es tomar una simbolización y mediarla en diversos medios, con sus características y especificados particulares. Esta simbolización se presenta a manera de lo que Genette (1989) llama relato, el enunciado narrativo, el discurso oral o escrito que entraña la relación de un acontecimiento o de una serie de acontecimientos"(pág. 81) que se despliega en diversas plataformas, obligando al consumidor indagar en estas para una mejor apreciación del relato.

No se debe confundir relato con historia y narración. Aunque en las citas de otros autores se le llame historia o narración al relato, hay que hacer hincapié en la diferencia que Genette postula para un mejor análisis (Genette, 1989). En cuanto a la primera, hace referencia al orden cronológico de lo que se ve contado del relato en " $\mathrm{x}$ " medios, y la narración supone la manera en que el narratario de un relato transmite la historia. "La idea de transmedialidad implica la explotación de la historia narrativa en distintos soportes y medios, favoreciendo con ello la adaptación del mensaje" (Amoros; Comesaña, 2016, p.166).

No es solamente consumir en varios medios algún tipo de narrativa, sino comprender narrativas que la suma de esas mediaciones individuales forman una narrativa transmedial, como Jenkis postula: "La transmedialidad representa un proceso donde los elementos integrales de una ficción se dispersan sistemáticamente a través de múltiples canales con el propósito de crear una unificada y coordinada experiencia de entretenimiento" (Jenkins, 2007), pero no determina ver la simbolización respecto a un producto en toda su transmedialidad para ser comprendida, "la revolución que supone el transmedia radica en que los soportes $\mathrm{y}$ medios actúan de manera global, pero también de manera independiente (Jenkins, 2007), de modo que no es necesario consumir uno para poder acceder a otro" (Amoros Pons Comesaña Comesaña, 2016, pág. 167). Así la transmedialidad es un hilo conductor que se despliega en diversas plataformas, empezando y terminando en un punto final de ambos productos.

Existen distintos productos que han sido transmediados, para una mejor ejemplificación se tomará la saga Injustice de la compañía DC. Para después indagar la manera en que los seguidores conocen que, a pesar de ser medios distintos, son un solo relato, por medio de una etnografía virtual, a través de grupos de Facebook, que fueron seleccionados previamente, por sus características particularmente centradas al consumo, intercambio y creación de contenidos, memes, fotos, debates, audiovisuales, por mencionar algunos, que se puede asegurar que son una comunidad emergente de conocimiento en la red, con sus propias reglas y leyes de pertenencia, políticas de admisión y de comportamiento, para con el grupo como para con sus integrantes comunitarios, sostenidos en lo que dicta Facebook al respecto, pero más allá de esas normas comunitarias, como normas propias de los seguidores de la franquicia transmediática y multimediática.

\section{Injustice}

Acorde al sitio web SMASH (2020), DC Comics es una editorial de cómics estadounidense (Párr.1), parte de $D C$ Entertainment, empresa bajo el mando de Warner Bros. Fue creada bajo el nombre de National Allied Publications en 1934 por Malcom Wheller-Nicholson (Fuentes, 2014), para luego cambiar a DC Comics en 1937, sus iniciales son abreviatura de Detective Comics, uno de los títulos más famosos de la empresa (Melrose, 2009). Es la casa de conocidos personajes como Superman, Batman, Wonder Woman, Flash, Linterna Verde, Aquaman y demás.

De los cómics de DC Injustice: Gods Among Us es originalmente un videojuego de peleas lanzado el 16 de abril del año 2013, para las plataformas Xbox 360, PlayStation 3 y Wii U, en el cual los personajes del universo DC luchan. No se abordará aquí la secuela, pero se deja escrito de su existencia.

El relato está transmediado en dos formas: Cómic y videojuego. El cómic se lanzó el 15 de enero del 2013 a septiembre del 2016 en formato físico y digital (Taylor, 2012) constan de cinco volúmenes llamados años, donde cada año consta de 36 cómics; cada uno de 22 páginas aproximadamente; con un anual de 38 páginas, que relatan 


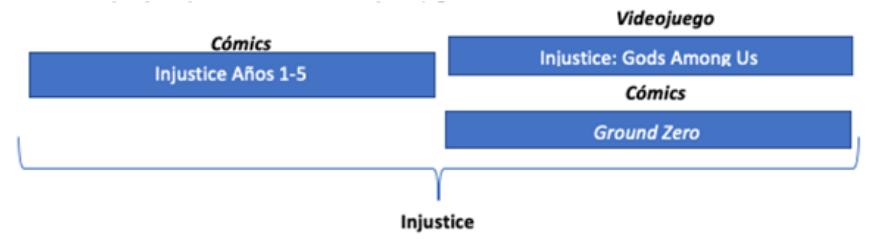

Figura 1. Elaboración propia.

lo que culminará en el inicio del videojuego y a su vez el volumen Ground Zero de 24 números (Torres, 2018).

Los cómics relatan la forma en que Superman se volvió un dictador instaurando un régimen mundial totalitario, acabando cuando la resistencia que está en contra de Superman, dirigida por Batman, logra teletransportar a una liga de la justicia que sigue unida de un universo alterno a su universo, dicho fin es el inicio del videojuego Injustice, en este, el relato transcurrirá en los confrontamientos que los superhéroes van teniendo, desarrollando el relato hasta su final, en el que el Superman del universo alterno se enfrenta al dictador, aislándolo en una zona que inhabilita sus poderes. Ground Zero relata los acontecimientos del videojuego desde la perspectiva del personaje Harley Quinn. De esta forma, se tiene que el megarelato entendido consta desde el inicio de cómic 01 de Injustice Año 1, hasta el final del videojuego Injustice: Gods Among Us y paralelamente Ground Zero.

A pesar de ser dos medios distintos -cómic y videojuegonarra un mismo relato -que ya se denominó como megarelato-, sin embargo, al ser la narración un discurso, cada relato se nos narra de forma distinta por la mediación en que se emite.

Cada mediación supone su propia semiótica, la del cómic cuenta con cuatro: "códigos lingüísticos, icónicos, cromáticos y gráficos" (Cuñarro Finol, 2013, pág. 268). Siendo los primeros dos códigos los que más peso tienen -generalmente-, afirmando lo que Cuñarro y Finol (2013) postulan al formarse un código de mayor complejidad y universalidad que ayudará a la mediación del cómic.

Algunas de las convenciones que Gubern y Gasca dijo en 1988 citado en Cuñarro Finol (2013), "reglas seguidas para facilitar la relación entre el autor y el lector" (pág. 271) son:

1.- "Globos" Que son un "indicador fonético" (Cuñarro Finol, 2013, pág. 271), y que regularmente posee una forma de óvalo, leyéndose bajo las mismas convenciones occidentales, de izquierda a derecha y de abajo a arriba, connotando el decir del personaje, si el globo posee forma de nube, se tratan de reflexiones/pensamientos del mismo.

2.-"Didascalia": También llamado cartucho, es otro indicador fonético de forma rectangular que el texto que enmarca da información del contexto del relato, se "le atribuyen dos funciones, la de anclaje, si aclara el contenido de la imagen, y la de conmutación, si facilita la continuidad narrativa" (Cuñarro Finol, 2013, pág. 272):

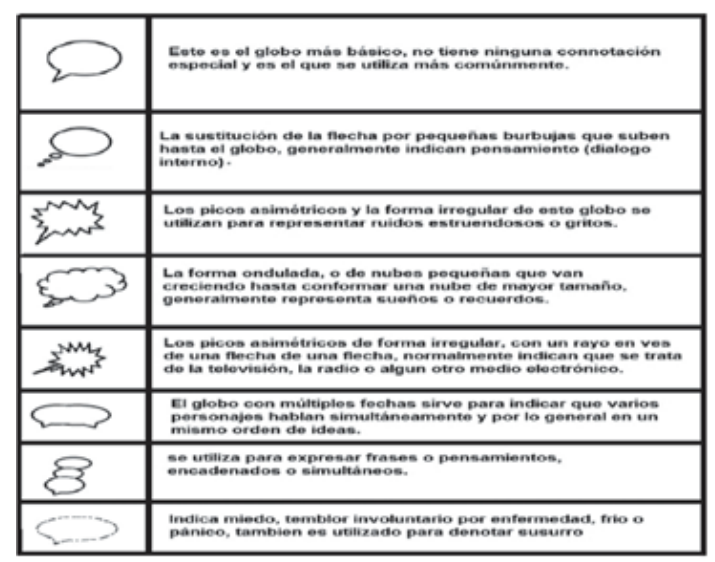

Imagen 1: Cuadro de globos (Cuñarro, L Finol, J.E., 2013, p. 273)

El cómic posee en gran parte de sus números la figura del "meganarrador", lo que supone que alguien narra los acontecimientos que ocurren en el relato sin nunca llegar a aparecer, esta instancia es usada por Genette, en la categoría modo, "[...] se refieren a la forma como se encuentra implicada en el relato la propia narración [...] la situación o instancia narrativa, y con ella sus dos protagonistas: el narrador y su destinatario"(Genette, 1989, pág. 86). Aunque hay números, como en el año uno, 9, en donde las didascalias del cómic introducen a un narrador (IMAGEN 2) que al final del mismo número se revela (IMAGEN 3). 


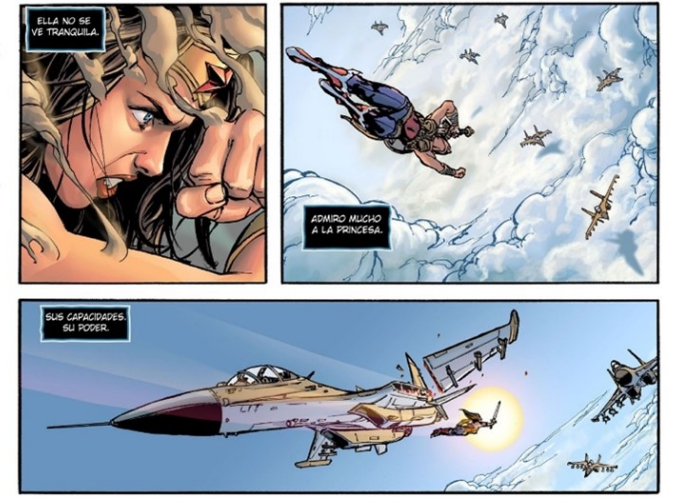

IMAGEN 2 (Taylor, Tom, 2013, p. 2)

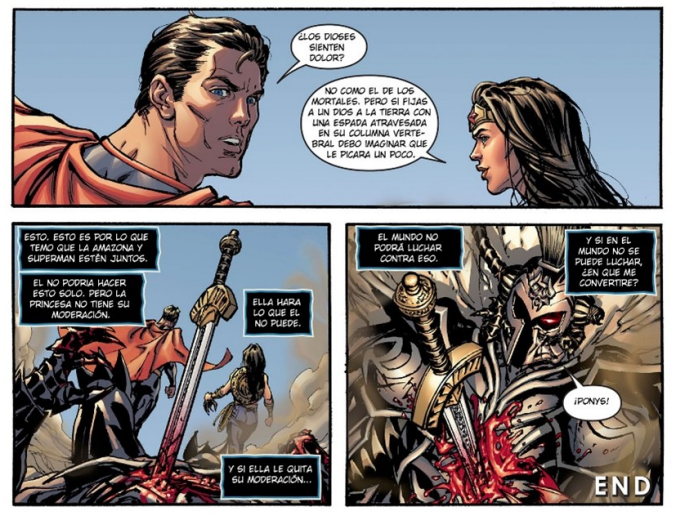

IMAGEN 3 (Taylor, Tom, 2013, p.12)

El videojuego supone también su propia complejidad, siendo una el desplazamiento del "jugador-personaje" al "narrador-personaje" (Martínez, 2007). La narrativa de Injustice está determinada mayormente por una narración lineal de "historias cerradas, relatos preestablecidos y la hegemonía de un narrador" (Martínez, 2007, pág. 12). El personaje que usa el jugador es quien va narrando los acontecimientos con la diferencia que el videojuego viene acompañado de una serie de películas que relacionan los diversos enfrentamientos que permitirán el desarrollo del relato. De nuevo entra la figura del "meganarrador" aquí en su totalidad.

\section{Resultados preeliminares de la metodología compleja: etnografía virtual para indagar la narrativa dispersa}

Es un problema complejo de abordar, pero pese a ello, internet resulta un espacio donde convergen diversos campos donde los usuarios interactúan de forma similar a la realidad;
[...] dan pie a la producción de páginas web como forma de acción social [...] la habilidad de reconocer ello como una forma de acciones sobre el mundo es una de las disposiciones culturales necesarias para que el uso de Internet tenga sentido y en ciertos casos logre tal compromiso e intensidad. (Lascano, 2012, pág. 115)

Como tal, esto es una aproximación realizada, lo que se denomina etnografía virtual, a partir de grupos de fan de DC Comics por la red social de Facebook, un estudio empírico de encuesta virtual de cuatro preguntas centradas en conocer la manera en que consumieron los dos productos que conforman la saga de Injustice.

Internet como objeto de estudio resulta complicado de concretar [...] porque sus fronteras son difícilmente reconocibles y su influencia e importancia en los social son amplias, situación que siempre planta un reto mayúsculo al intentar delimitar con precisión qué investigar de Internet y cómo. (Rodríguez, 2013, pág. 2)

A partir de la Acción Discursiva Radiofónica, (Sadi Durón Navarro Zamora, 2019, pág. 181) y que aquí es adaptada por Sadi, para el acercamiento mediático y transmediático, dice que la teoría de medios de Jensen sirve para describir la interacción humana a través de las cosas en que la gente llega a saber que estos productos son parte de un mismo relato, "la comunicación es acción social y en sí acción comunicativa, además de discurso y prácticas estructuradas desde los dominios social (y cultural) psicológico y biológico" (Sadi Durón Navarro Zamora, 2019, pág. 181).

Como parte del acercamiento inicial que marca la metodología de la acción discursiva mediática, que desde la adaptación de los preconcebidos de Haidar (2006), y que fueron adoptados en la metodología de la Acción Discursiva Radiofónica (Sadi Durón Zapata Salazar, 2020), se plantea que se debe de conocer al sujeto a investigar y sus capitales culturales y simbólicos; pero primero se debe desarrollar una encuesta virtual para obtener datos empíricos sencillos.

Los resultados del acercamiento empírico de esta primera etapa, a cargo de Jorge Baca como parte de estos grupos en donde ha estado más de dos años interactuando, es en donde se desarrolló una encuesta virtual de cuatro preguntas usando el portal Survey Monkey como plataforma de desarrollo; se les hizo llegar el link a 100 sujetos en publicación directa 
en el muro de los grupos de Facebook. Los resultados indican datos sobre el cómo consumen el medio a partir de la transmedialidad del videojuego al comic, y viceversa. A la pregunta de cómo se enteraron que el videojuego de Injustice, fue primero y cómo la series de cómics Injustice fueron después.

La primera pregunta fue ¿eres Fanático de DC Comics?, el $90.91 \%$ indicaron que sí. La pregunta segunda fue: ¿por qué medios te enteraste que los cómics y los videojuegos pertenecían al mismo relato? Los seguidores de DC Comics se enteraron mediante videos (principalmente en la plataforma de YouTube) con un $27 \%$ y cuentas oficiales (principalmente por Facebook) con un 26\% de la existencia de videojuego y cómics como parte de un mismo relato. Acorde a los niveles Jensen (2014), se sitúa en metatecnologías, donde "los medios digitales unen el texto, la imagen y el sonido [...] integran las formas de comunicación de uno-a-uno, uno-a-muchos y muchos-a-muchos"(p.22). La siguiente pregunta ¿qué productos de la saga Injustice consumiste primero? el $66 \%$ contestó "cómic" y el $91 \%$ videojuegos. El papel de los fans en la interacción de los grupos para enterarse de "las novedades" o "datos canónigos" se refleja en que el $96 \%$ se enteró a través de la publicación de un fan con mayor conocimiento en un posteo del grupo o red social extra (YouTube de fans, publicaciones no oficiales), posteada en el propio grupo por otro fan. Lo interesante es que se confía en el fan tanto como en la fuente oficial pero la fuente oficial pocas veces resulta ser la fuente primaria del conocimiento extra. Entonces hay una comunidad de conocimiento, información y comunicación, que construye cibercultura.

La primera aproximación cumplió su cometido: conocer el objeto mediatizado y mediado y cómo se apropiaron de él y la construcción de un conocimiento nuevo, con base a interacción de la comunidad emergente de conocimiento (Almaguer Kalixto, 2013).

Reconocer agentes de tres grupos de Facebook que interactúan entre sí: Sociedad DC Comics, DC Universe vs Marvel Comics y DC Comics Grupo Mx; los cuales se está en proceso de seguimiento para destacar sus características particulares como agentes transmediáticos, de grupos de audiencia activa, como agentes de una comunidad emergente de conocimiento, y que en tanto consumidores de cómics, tanto de DC, como de Marvel, y Star Wars, se pueden diferenciar en contenidos, pero ser similares en acciones, dentro de grupos entendido como comunidades emergentes de conocimiento, que comparten sociocogniciones, valores, emociones y gustos, así como un sistema de cibercultura entendida como sistema de información, comunicación y conocimiento que desde la red social Facebook groups, trasciende el internet y las intersubjetividades, a partir de la acción de crear contenidos y compartirlos a otros afines.

\section{Descripción breve de los grupos:}

\subsection{Grupo uno: Sociedad DC Comics}

Es un grupo de tipo privado y visible, con 85,322 miembros; nueve administradores; y cinco moderadores.

Fundado el 9 de diciembre del 2016, con la función de compartir y publicar contenido exclusivo de DC, así como entablar relaciones con otros seguidores de la compañía (Sociedad DC Comics, 2020).

Poseen 10 reglas publicadas en su cuadro de información: Respetar las creencias religiosas y filosóficas, gustos, raza, género, etc. de los demás miembros (netamente importante). Se sugiere un compromiso por ayudar a quien lo necesite. La persona tóxica que amedrente en contra de algún miembro, por no tener conocimientos profundos en cómics, será amonestado. Se exige respeto a DC Comics y todo lo que encierra. Sean conscientes, si están en un grupo dedicado a DC, respétenlo. Solamente se aceptan críticas constructivas con argumentos, opiniones y referencias legítimas. Se permite publicar sobre: Wildstorm, Dynamite (Dark Horse Cómics), Image, IDW, ya que son sellos adquiridos por DC. Los Domingos se permiten publicaciones Off-Topic (otras editoriales, series o cualquier otro tipo de asuntos). Prohibido los spoilers, con los cómics y series debes esperar una semana. y con las películas tres semanas, A menos que publiques con un aviso y una imagen sin spoilers. Nada de acosos. No toleramos insultos machistas, feministas y homofóbicos. Si violas esta regla serás baneado inmediatamente porque todos merecemos respeto. Se prohíbe postear y compartir pornografía, temas religiosos, y temas políticos. No se permite usurpar contenido ajeno, y postearlo como suyo sin antes ser citado. No publicar datos personales de otra persona, como fotos, credenciales, pasaporte, etc (Sociedad DC Comics, 2020). 
El grupo posee numerosas publicaciones, se comparten videos e imágenes, mayormente tomadas de otros grupos, todas afines a la compañía de cómics, ya sea de sus series, películas, cómics, videojuegos. Los miembros son quienes sueles compartir y mantener activa la página, pero en su mayoría, suele ser contenido creado de otras páginas, dándole difusión para que los usuarios del grupo reaccionen. Pocas veces lo publicado en el grupo genera que los miembros comenten en las publicaciones, limitándose a reaccionar.

\subsection{Grupo dos: DC Universe vs Marvel Comics}

Es un grupo de tipo privado y visible; con 72,262 miembros; cinco administradores y 13 moderadores. Fundado el 13 de septiembre del 2014, con el objetivo de realizar “combates hipotéticos", pero a pesar del nombre del grupo, se permite involucrar personajes de otros contenidos, como el manga o anime. Dentro de las reglas del grupo está no compartir comercialización de artículos y la promoción de grupos y organizaciones sin fines de lucro, así como publicaciones sexualmente sugestivas o pornográficas (DC Universe vs Marvel Comics, 2020).

Este grupo posee un álbum con dos imágenes sobre la manera en que se desarrollan los "combates hipotéticos":

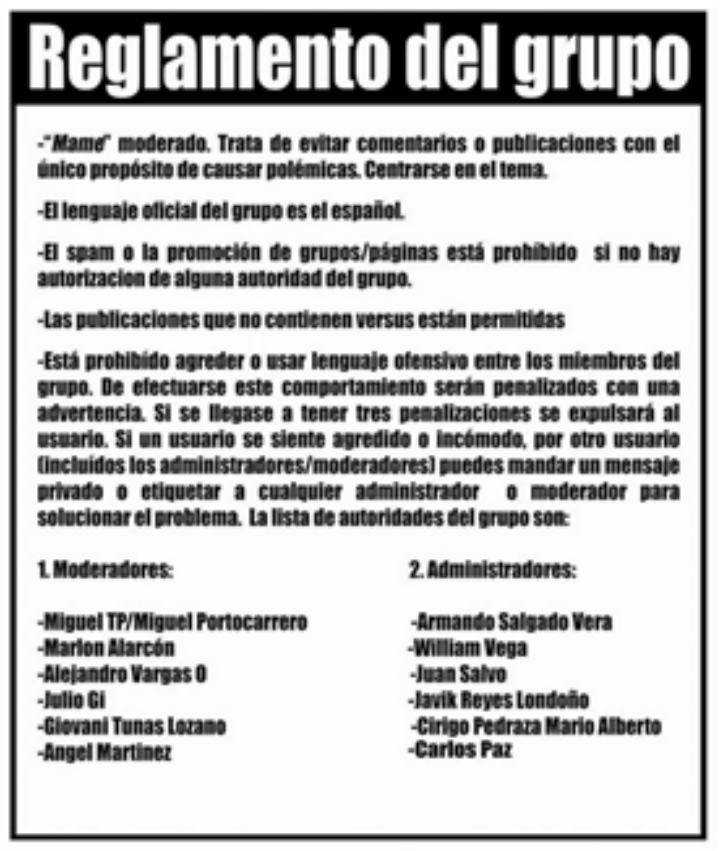

El grupo se mantiene activo mediante publicaciones que los mismos usuarios originan, los "combates hipotéticos", los cuales originan una numerable cantidad de comentarios en los que los miembros van imaginando sobre cómo sería dicho combate. También se suele compartir contenido de otras páginas generalmente relacionado a cómics.

El grupo no mantiene una exclusividad en cuanto a los combates, sean de las compañías Dc y Marvel, pues dejan que otros personajes de otras compañías sean puestos como parte de los combates.

\subsection{Grupo tres: DC Comics Grupo Mx}

Es un grupo de tipo privado y visible, con 17,184 miembros; ocho administradores y un moderador. Fundado el 27 de noviembre del 2015, con el propósito de compartir el gusto por la compañía DC Comics, el grupo remarca qué personajes, nombre e imagen pertenecen a dicha marca. En su información posee ubicación en México, cosa que los anteriores grupos no delimitaban (DC Cómics Grupo Mx, 2020).

El grupo tiene un recuadro específico de reglas, las cuales son: 1. Sé amable y cordial: Para fomentar un entorno agradable debemos tratarnos con respeto. Puedes debatir sobre diversos temas siempre que seas cordial con los demás. 2. No hagas bullying ni uses lenguaje ofensivo: Asegúrate de que todos se sientan seguros. No se permite el bullying ni los comentarios degradantes sobre la raza, la religión, la cultura, la orientación sexual, el género o la identidad. 3. No publiques promociones ni spam: En este grupo no se permiten la autopromoción, el spam ni los enlaces irrelevantes, en caso de hacerlo serás eliminado y bloqueado definitivamente de todos los grupos donde tiene presencia ComicCrew. 4. Respeta la privacidad de los demás: Para formar parte del grupo se requiere confianza mutua. Las conversaciones sinceras y abiertas no dejan de ser confidenciales y privadas. Lo que se comparte en el grupo no debe salir de él. 5. Están permitidas las ventas: Tanto como vendedor y/o comprador sus tratos son a nivel personal y el grupo, ni administradores son responsables de los tratos comerciales que se hagan dentro y fuera del mismo. 6. No spoilers: Aplica en películas, series, cómics, etc. Deberás esperar el veto a una semana del estreno. A menos que publiques con un aviso y/o imagen "CON SPOILERS". 7. Prohibido el acoso: No toleramos insultos machistas, clasistas, feministas y homofóbicos. Si violas esta regla serás baneado inmediatamente sin previo aviso. 8. No Pornografía: Se prohíbe postear y compartir pornografía. Este 
tema es muy delicado, entendemos que el cine y series tiene vínculo directo con el erotismo, cuidemos de no sobre pasar la línea de lo explicito. 9. Respetar identidades: No publicar datos personales de otra persona, como fotos, credenciales, pasaporte, etc. 10. Promoción de páginas y grupos

Si eres creador de alguna página y/o grupo, no puedes compartir tus contenidos, excepto pidas permiso a la administración, de otra forma serás baneado definitivamente de todos nuestros grupos. (DC Cómics Grupo Mx, 2020).

El grupo suele tener publicaciones originadas por los mismos usuarios, pero también compartida de otras páginas, mantiene la exclusividad en la compañía DC Comics.

Se suelen compartir videos e imágenes, ya sea de sus series, películas, cómics videojuegos.

La comunicación, aunque parezca sólo entretenimiento o lúdica, guarda en sí misma, sus mensajes y acciones de los agentes de todos los niveles, la raíz misma de las construcciones mentales y los recursos culturales de una sociedad red intercultural que comparte más contenidos, acciones e ideas de las que hemos creído hasta hoy.

\section{Conclusiones del primer acercamiento}

Esto es una primera aproximación de un estudio mucho más amplio que constará de el análisis de los grupos donde aparece. La complejidad que se intentó obtener en esta investigación por etapas o fases de ir y venir con los agentes de los medios, tendrá sus tiempos y modalidades acorde al nuestro modelo de acción discursiva mediática que primero exige conocer el camino a seguir.

Los contenidos de "super héroes" han trascendido la ficción del cómic, hacia otras plataformas y han sido resignificados por su propios consumidores y audiencias. Aquí se describió una primera aproximación al contenido de algunos de estos productos transmediáticos, pero aún falta la aproximación a los agentes.

Cabe aclarar que una investigación de tipo compleja, no permite hipotetizar sobre los resultados a encontrar, pero en este primer acercamiento se vio en las propias acciones del grupo, los intentos para librarse de problemas que existen en la interacción tan amplia entre sujetos con gustos afines y que van desde el abuso o violencia verbal, visual, simbólica, hasta la abierta y franca confrontación entre sujetos. Esto es lo que apenas se observa. Cada grupo de Facebook es un universo propio con reglas similares, para problemas recurrentes en todos, que dibujan la identidad virtual y las problemáticas sociales de quienes los integran.

Por ello se presentó el primer acercamiento realizado y que guiará a más acercamientos posteriores a los agentes de los grupos de Facebook seleccionados y que serán parte del estudio; de momento se observó parte del objeto transmediado y el sostén teórico-metodológico que permitirá abordarlo complejamente.

\section{Referencias}

Almaguer Kalixto, P. E. (2013). Cibercultur@ e Investigación-Acción Participativa: intersecciones metodólogicas para el desarrollo de comunidades emergentes del conocimiento Local. ESTUDIOS SOBRE LAS CULTURAS CONTEMPÓRANEAS, XIX(37), 129-164.

Amoros Pons, A., Comesaña Comesaña, P. (2016). Cartoons, publicidad y transmedialidad. Cuadernos informativos., 165-180. Antonio, P. C. (2009). Sociología y ciencias sociales en y desde el mundo: el pensamiento latinoamericano ante el cambio de época. Controversias y Concurrencias Latinoamericanas ALAS Número 2, año 1, 15-36.

Barbero, J. M. (febrero de 2002). Jóvenes: comunicación e identidad. Pensar Iberoamerica, ISSN: 1683-3783(0), http://www.oei.es/pensariberoamerica/ric00a03.htm. Baudrillard, J. (2007). El sistema de los objetos. México: Siglo XXI .

Behar Rivero, D. S. (2008). Metodología de la investigación. Buenos Aires, Argentina: Shalom.

Bourdieu, P. (1997). Razones Prácticas, sobre la teoría de la acción. Barcelona, Barcelona, España: Anagrama.

Bourdieu, P. (06 de 06 de 2006). Pierre Bourdieu blogspot. Recuperado el 11 de 10 de 2011, de http://pierre-bourd ieu.blogspot.com/2006/06/repensar-el-movimiento-so cialpierre.html

Bourdieu, P. (2008). Capital Cultural, escuela y espacio social. México: Siglo XXI. Campos-Freire, F. (2015). Adaptación de los medios tradicionales a la innovación de los metamedios. El profesional de la información, 24(4), 441-450.

Cassirer, E. (2007). Antropología filosófica. México: Ed. Fondo de cultura económica.

Castells, M. (2001). Prologo: La red y Yo. En M. Castells, La era de la información (págs. 23-25). México: Siglo XXI. 
Cuñarro, L., Finol, J. E. (2013). Semiótica del cómic: códigos y convenciones. UNED. Signa: Revista de la Asociación Española de Semiótica, 22. http://revistas.uned.es/index .php/signa/article/view/6353/6086

DC Cómics Grupo Mx. (2020). Reglas de los administradores del grupo. Facebook/groups. Recuperado de https://ww w.facebook.com/groups/517477628421630/about

DC Universe vs Marvel Comics. (10 de noviembre, 2016). Reglamento. Facebook/groups. Recuperado de https: //www.facebook.com/media/set/?set=oa.1119085328 205466\&type $=3$

El País. (31 de agosto de 2009). Disney compra Marvel por 2.800 millones. El País. https://elpais.com/economia/20 09/08/31/actualidad/1251703979_850215.html

Elleström, L. (2017). Transfer of media characteristics among dissimilar media. Palabra Clave, 20(3), 663-685. Fuentes, G. V. (2014). Breve historia del cómic. Ediciones Nowtilus SL.

Galán Ugartemendía, J. I. (2014). La Transmedialidad. Una nueva gramática para el sujeto complejo (revisitando La Aldea Global). Actas del Coloquio sobre Narrativas Transmediáticas y Construcción de los Asuntos Públicos, 38-41.

García Sánchez, J. J. (2017). El prefijo latino trans-en su continuación románica y en su aplicación toponímica. Semántica, Lexicología y Morfología, 123-35.

García, Rolando. (2006). Sistemas Complejos, Conceptos, método y fundamentación epistemológica de la investigación interdisciplinaria. Barcelona, España: Gedisa.

Garza Cuarón, B. (1999). Significado. Ciudad de México, Distrito Federal.: Universidad Nacional Autónoma de México.

Gaudreault, André; Jost, François. (1995) El relato cinematográfico. Cine y narratología. España. Ediciones Paidós Ibérica.

Genette, G. (1989). Figuras III. (C. Manzano, Ed.) Barcelona: Lumen.

Geertz, C. (1973). La interpretación de las culturas. México: Gedisa.

Guarinos, V. (2007). Transmedialidades: el signo de nuestro tiempo. Revista Internacional de Comunicación Audiovisual, Publicidad y Literatura, 1 (5), 17-22.

Habermas, J. (1981). Historía y Crítica de la Opinión Pública. (2a Edición. ed.). México, Ciudad de México, México: Gustavo Gili.

Haidar, J. (2006). Debate CEU-Rectoría Torbellino pasional de los Argumentos. (Vol. Colección Postgrado). México, CDMX, México: UNAM.

Hine, C. (2004). Etnografía virtual. Barcelona, España: UOC

Huizinga, J. (2007). Homo Ludens. Madrid: Ed. Historia Alianza Emecé.
Jenkins, H. (2007). HenryJenkis.org. Obtenido de Confessions of an Aca-Fan: The Oficial Weblog of Henry Jenkins.: http://henryjenkins.org/2007/03/transmedia_storytellin g_101.html

Jensen, K. B. (2014). La comunicación y los Medios, Metodologías de investigación cualitativa y cuantitativa. (M. Sánchez-Ventura, Trad.) México, México, México: Fondo de Cultura Económica.

Krotz, F. (2009). Mediatization: A concept With Wich to Grasp Media an Social Change. En L. Kunt, S. Livingstone, Mediatization, concepts, changes, consecuences. Peterlang.

Latour, B. (1998). De la mediación técnica: filosofía, sociología, genealogía. . En M. Domenéch, F. Tirado, Sociología simétrica. Ensayos sobre ciencia, tecnología y sociedad. (págs. 249-302). Barcelona: Gedisa.

Lascano, N. W. (2012). Reseña del libro La etnografía virtual revisitada: Internet y las nuevas tecnologías digitales como objetos de estudio, de Christine Hine. Revista Latinoamericana de Metodología de las Ciencias Sociales, 2(2), 109-116.

Madriaga Orozco, C., Abello Llanos, R., Sierra García, O. (2014). Redes Sociales, infancia, familia y comunidad. Barranquilla, Colombia.: Universidad del Norte.

Manm, H. (2002). Introducción a la Antropología General. MÉXICO: ALIANZA.

Martínez, D. S. (2007). Los videojuegos. Consideraciones sobre las fronteras de la narrativa digital. Cuadernos de literatura, 12(23), 13-26.

Melrose, Kevin. (2009). DC Entertainment: What we know so far. CBR. Recuperado de https://www.cbr.com/dc-e ntertainment-what-we-know-so-far/

Mateo Rodriguez, J. M., Bollo Manet, M. (2016). La región como categoría geográfica. (Vol. Versión Digital Descargada 2005 2019). México, CDMX, México: UNAM-CIGA.

Orozco, G. (1997). Medios, audiencias y mediaciones. Comunicar, (8) Marzo,. España, Hulva, Redalyc. Vid: https://www.redalyc.org/pdf/158/15800806.pdf

Peicer, C. S. (1986). La Ciencia de la Semiótica. Buenos Aires, Argentina.: Nueva Visión.

Peña Timón, V. (2003). La matriz ficciones como estrategia creativa en la adaptación audiovisual. ICONO 14, Revista de comunicación y tecnologías emergentes, 1(2), 1-10. 13 de Marzo. https://www.redalyc.org/articulo.o a?id=5525/552557616008

Piaget, J., Inhelder, García, R., Vonéche, J. (1981). Epistemología genética y equilibración. Madrid, España, España: Editorial Fundamentos.

Peicer, Charles S. (1986). La Ciencia de la Semiótica. México. Nueva Visión.

Quijano, A. (2000). Colonialidad del Poder, Eurocentrismo y América Latina. En E. L. (Ed), La colonialidad del Saber: Eurocentrismo y ciencias sociales-perspectivas 
latinoamericanas. (págs. 201-245). Buenos Aires: CLACSO.

Rodríguez, J. M. (2013). Etnografía de lo virtual: experiencias y aprendizajes de una propuesta metodológica para investigar internet. Razón y palabra, 18-83.

Rodríguez, Á. C. (2012). Los sufijos nominalizadores-ción,-sión,-miento/-mento en el español actual. Revista Cálamo FASPE, (60), 47-52.

Scollon, R. (2003). Acción y texto: para una comprensión conjunta del lugar del texto en la inter(acción) social, el análisis mediato del discurso y la acción social. En R. . Wodak, Métodos de Análisis Crítico del Discurso. (págs. 205-266). Barcelona, España, España: Gedisa.

Sadi Durón, J., Navarro Zamora, L. (2019). Divulgación de la ciencia en la radiodifusión universitaria: acción discursiva radiofónica. En L. (. Navarro Zamora, La comunicación de la Ciencia. Miradas interdisciplinarias con responsabilidad social (págs. 207-230). México: Colofón. Ediciones académicas.

Sadi Durón, J., Zapata Salazar, J. (Edición Invierno de Enero de 2020). La radiodifusión universitaria: acción discursiva radiofónica para la divulgación de la ciencia. Ambitos Revista Internacional de Comunicación, ISSN:1139-1979 (E-ISSN: 1988-5733 DOI: HTTP://DX.DOI.ORG/1012795/AMBITOS), 87-108.

Sadi Durón, J.(2006) La radio Universitaria Estudiantil, la comunicación alternativa. México. UNAM el autor.

Sandoval Casillimas, C. (1996). La investigación cualitativa. Bogota: ICFES.

Sassen, S. (2010). Las Redes digitales, la autoridad Estatal y la Política. En S. Sassen, Territorio, autoridad y derechos (págs. 411-472). Buenos Aires: Katz.

SMASH. (2020). DC Comics. SMASH. Recuperado de https: //www.smashcomics.com.mx/collections/dc-comics-m exico

SMASH. (2020). Marvel. SMASH. Recuperado de https: //www.smashcomics.com.mx/collections/marvel-comi cs-mexico

Sociedad DC (2020). Reglas de usuarios. Facebook/groups. Recuperado de https://www.facebook.com/groups/Grup oSociedadDC/)México.

Taylor, Tom. (2013). Injustice: Gods Among Us Vol.1 9. Estados Unidos, Nueva York. DC Comics.

Toledo, J. A. H. Mundo Móvil: de la hipermediatización a la transmedialidad.

Strathern, M. (1996). Cutting the network. Journal of the Royal Anthropological Institute, 517-536.

Taylor, T. (16 de 10 de 2012). announcing-injustice-gods-among-us-the-comic-series/. Obtenido de Internet Archive: WayBackMachine; Web Archive. com: https://web.archive.org/web/2013011606 5059/http:/www.tomtaylormade.com/2012/10/announc ing-injustice-gods-among-us-the-comic-series/
Thompson, J. B. (2002). Ideología y cultura moderna, Teoría crítica social en la era de la comunicación de masas. México: Universidad Autónoma Metropolitana.

Torres, G. (19 de 10 de 2018). Smashmexico.com.mx. Obtenido de ¿De que trata Injustice: Gods Among Us?: https://www.smashmexico.com.mx/dc/injustice-gods-a mong-us-comic-trama-historia-completa/

Vigotsky, L. (1977). Pensamiento y lenguaje. Teoría del desarrollo cultural de las funciones psíquicas. (M. M. Rotger, Trad.) Madrid, Madrid, España: Pléyade.

Vigotsky, L. S. (1978). El desarrollo de los procesos psicologicos superiores. (Primera edición ed.). Barcelona, Barcelona, España: Crítica, Grupo Editorial Grijalbo.

Wallerstein, I. (1998). Llamado a un debate sobre el paradigma. En I. Wallerstein, Impensar las Ciencias Sociales (págs. 257-277). México: Siglo XXI UNAM CIICH.

Wallerstein, I. (1998). Sistemas Historicos como sistemas complejos. En I. Wallerstein, Impensar las Ciencias Sociales (págs. 249-256). México: Siglo XXI UNAM CIICH.

Wallerstein, Immanuel. (1995). Abrir las ciencias sociales. Informe de la comision Gulbenkian para la reestructuración de las ciencias sociales. México: SivloXXI, Centro de Investigaciones interdisciplinarias en Ciencias Sociales y Humanidades UNAM.

Žižek, S. (1999). El ciberespacio, o la inteolerable cerazón del ser. En S. Žižek, El acoso de las fantasías (págs. 148-163). México, México: Siglo XXI. 